\title{
Informática, controle social e poder
}

* Comunicação do Vo Congresso Nacional dos Sociólogos. Universidade do Estado do Rio de Janeiro, Rio de Janeiro, maio, 1984.

Maria Teresa de Oliveira Escola Nacional de Saúde Pública - FIOCRUZ - RJ
Recebido para publicação em $21 / 06 / 85$.
1. A informática pode ser vista como a aplicação do processo científico à informação ou, por outras palavras, como a continuação, no campo da informação, da organização própria à ciência. Não da ciência num sentido lato (que compreenderia todo e qualquer tipo de informações), mas à forma particular de saber ocidental. A tecnologia é um aspecto dessa organização científica especial, constituindo sua base técnica ou base material.

$\mathrm{Na}$ medida em que o social se relaciona com essa ciência - e a reflete - com o tipo de representação ou informação por ela privilegiado, a informática é, também, um controle social. Em outras palavras, é a cientifização do controle.

A informática seria o produto da aplicação, no campo social, da relação real/representação comum a essa ciência, a esse controle e ao Estado. De certo modo é contemporânea das técnicas de controle social e do Estado, na forma em que hoje se os conhece. Conforme o indica a reflexão da Escola liderada por Michel Foucault, sobre a sociedade disciplinar, quando são descritas as formas adotadas por essa sociedade, para dobrar os seres humanos às suas exigências.

Nos séculos XVII e XVIII, desenvolvem-se na Europa novas técnicas destinadas a reger as relações entre o tempo, os indivíduos e suas forças, de maneira a capitalizar o tempo de cada um, de tal modo que ele seja passível de utilização e controle. Para tanto, foram adotados processos disciplinares inspirados nos procedimentos religiosos e aplicados à organização corporatista e manufatureira. A compartimentação do tempo, detalhista, analítica e rica em regula. mentos, se destinou a "economizar" o tempo da vida, acumulando-o de forma útil, e a exercer poder sobre as pessoas através do tempo assim disposto.

$O$ processo que se aplica inicialmente aos soldados e religiosos, visa ao conjunto dos "homens-máquinas" e, portanto, também os trabalhadores, os doentes, os estudantes.

O grande movimento de articulação das técnicas disciplinares corresponde à transição histórica de dois modos de produção, ao desfecho de uma era e à abertura da seguinte. O modo de produção capitalista que iria se implantar à custa de convulsões sociais exigia, para o seu funcionamento, uma nova ordenação social, na qual massas desorganizadas, desordeiros individualistas, ritmos lentos, gastos inúteis e até gestos gratuitos não deviam mais ter lugar. $\mathrm{O}$ movimen- 
to de ordenação, agindo sobre as instituições - casernas, escolas, hospitais, fábricas, escritórios - devia assegurar o enquadramento geral da nova sociedade. Essa nova sociedade se assenta sobre o novo Estado que encontra na centralização e no controle os seus fundamentos mais característicos.

O Estado emergente, ao necessitar enquadrar grandes massas, aperfeiçoa as técnicas de controle, não somente através da ordenação minuciosa do tempo, mas a partir da coleta, reunião e organização das informações. Esse grande movimento caracteriza, hoje, não apenas as instituições de controle formal como a justiça, a polícia, o exército, o fis$c o$, mas passa a permear a sociedade em todas as suas instâncias. Nesse processo, a intervenção da informática traz à luz um conjunto de técnicas capazes de tratar eletronicamente grandes quantidades de informações. Ela é, assim, o cumprimento desse processo, ao mesmo tempo em que é a sua evolução mais recente e espetacular. A execução dessas técnicas se apoia numa variedade de aparelhos cada dia mais sofisticados e de inovações tecnológicas, como as linguagens do computador, cujo acompanhamento, senão o domínio, se impõe a todos aqueles que desejem se inserir na "nova" sociedade.

Por isso se pode afirmar que é a forma moderna do Estado que se perpetua e se cumpre na informática e por ela. $\mathrm{O}$ que há de realmente "novo" é a renovação da forma já existente de poder e controle social. O melhoramento que há é o desse poder e desse controle. Compreender, pois, a informática é tentar compreender essa relação e o relativo dessa novidade.

2. A informatização da Sociedade Brasileira - reflexos sobre a organização do trabalho e sobre o equilíbrio físico e psíquico dos trabalhadores.

Essas são as idéias gerais sobre as relações informática/ controle social/poder que presidiram a formulação do estudo ora em andamento. Esse estudo que se destina a uma dissertação de Doutorado pretende ser um pensar a realidade dessas relações, tal como elas se verificam atualmente na sociedade brasileira. Por outro lado, é um trabalho que se preocupa em distinguir os traços dessas relações no "concreto", numa instância em que os atores evoluem e se dão às relações sociais de produção.

Para tal, escolheu-se observar a esfera do trabalho que parece ser o campo privilegiado onde a larga aplicação da informática, através da presença dos aparelhos eletrônicos, primeiro se manifesta.

Para examinar: (1) os impactos da produção dos computadores junto a determinados setores da população; (2) as questões relativas especificamente aos efeitos da informática nos ambientes do trabalho; (3) as questões relativas ao 
equilíbrio físico e psíquico dos atores envolvidos nesse processo; (4) as relações do controle e (5) as al terações nas relações sociais dos atores, escolheu-se observar alguns aspectos do processo de automação bancária, numa pesquisa de campo junto aos trabalhadores da "última linha", ou seja, daqueles que de certa forma "padecem" a informatização. Nessa pesquisa, o tema da informatização da sociedade foi analisado a partir dos indicadores do controle social (privacidade e disciplina), da saúde (bem-estar físico e psíquico) e do trabalho (desqualificação profissional e relações com as máquinas).

$\mathrm{O}$ estudo se desenvolveu junto a um grande estabelecimento bancário comercial privado, que recentemente colocou terminais de computadores nas agências, à disposição do público, e onde o movimento diário passou a ser operado por terminais vinculados aos computadores centrais da empresa. Tais alterações foram precedidas de modificações na organização geral das agências, atingindo o tipo de trabalho aí desenvolvido, bem como os próprios papéis dos atores interessados.

A informatização dos serviços de atendimento representa um trunfo importante na concorrência, pois adquire clientes, aumenta o número de novas contas e, portanto, os lucros do banco. No caso ora em consideração, houve no mínimo uma duplicação do número de abertura de contas em cada agência que se informatizou.

Por isso mesmo, outros estabelecimentos bancários também passaram a automatizar seus serviços de atendimento ao público. Esta tendência caracteriza o setor bancário como uma ponta de lança para a introdução dos equipamentos eletrônicos na nossa sociedade, familiarizando largos segmentos da população urbana com as novas máquinas e sobretudo com as novas técnicas, contribuindo deste modo para a vulgarização da imagem do computador. Nesse processo, é digno de nota o amplo suporte oferecido pelos meios de comunicação, especialmente a TV, através de campanhas publicitárias e de filmes retransmitidos pelo vídeo.

Escolhido o estabelecimento e feitos os contactos indispensáveis, foi realizada a pesquisa de campo em três agências selecionadas por sorteio e localizadas nas Zonas Sul, Norte e Centro da cidade.

A amostra sobre a qual se trabalhou não foi estabelecida em função de critérios estatísticos ou probabilísticos. Reunindo-se a população das três agências selecionadas, extraiuse desta fração a correspondente aos dois grupos.

A amostra não pretendeu, assim, a representatividade em relação ao número de empregados do estabelecimento ou ao número de bancários, mas apenas visou a respeitar a proporcionalidade e o equilíbrio em relação aos critérios prefixa- 
dos aleatoriamente de posição hierárquica, sexo, faixa etária, tendo sido estratificada em relação a esses critérios. Em cada estrato, composto por todos os funcionários daquelas categorias nas agências, entrevistaram-se $44 \%$ das pessoas do grupo dos Chefes e $40 \%$ das pessoas do grupo dos Caixas. Foram escolhidas nas agências, mediante sorteio aleatório, as pessoas a serem entrevistadas.

As entrevistas se destinaram a colher material exclusivamente qualitativo. Elas nunca tiveram duração inferior a 60 minutos.

Foram feitas exclusivamente entrevistas abertas, obedecendo a roteiros de temas. Construiu-se um roteiro geral para as séries II (Chefes) e III (Caixas) e roteiros especiais para as séries I (Diretores), IV (Médicos e Especialistas) e V (Dirigentes Sindicais). A técnica escolhida foi a da entrevista livre, formulada como um diálogo aberto, tendo, porém, um fio condutor; em outras palavras, um roteiro. Os roteiros tiveram um tamanho que oscilou entre não menos de 80 e não mais de 86 questões. As perguntas versaram sobre: aspectos relativos às rotinas de trabalho e à ocupação, focalizando a situação funcional do trabalhador; aspectos relativos ao tema geral da informática, privilegiando-se as transformações que as novas tecnologias introduzem nas relações de trabalho; aspectos ligados ao controle do trabalho e do trabalhador, destacando-se as implicações eventualmente acarretadas pela introdução dos aparelhos eletrônicos e, finalmente, aspectos da saúde dos trabalhadores, destacandose a presença recente dos computadores nos ambientes laborais e sua influência. Quando da publicação da tese, as listas de questões, assim como os roteiros de temas e as listas de variáveis e indicadores serão apresentados.

Tratando-se de uma pesquisa fundamentada em metodologia basicamente qualitativa, a análise dos resultados obtidos dessa forma obedece à técnica da análise do discurso, tendo-se procurado organizar discursos específicos por categoria, tipo ou série.

Toda as entrevistas foram gravadas. Foram entrevistados os dois grupos-chave das áreas comerciais bancárias: o dos gerentes (incluindo tesoureiros e chefes) e o dos caixas, que são os grandes protagonistas do banco, por serem aqueles que manipulam diretamente o dinheiro. Por outro lado, são os que lidam com os terminais eletrônicos. Finalmente, constituem, do ponto de vista das relações de trabalho, os atores característicos do serviço bancário.

Além das duas primeiras séries, que forneceram o material.mais abundante, foram realizadas outras séries de entrevistas com os Diretores da área de informática do banco, com os profissionais do Serviço Médico do banco e com especialistas em saúde, para se obter as outras tonalidades que 
compõem o painel da pesquisa. Finalmente, foram ouvidos dirigentes sindicais, no intuito de resgatar o "perfil" do bancário no Rio de Janeiro, nas duas últimas décadas, e completar, assim, o estudo.

Tais entrevistas são complementares, tendo sido realizadas sem obedecer a qualquer critério de proporcionalidade. Cada entrevistado foi ouvido como informante privilegiado, isto é, como testemunha que, pela posição ocupada em relação ao problema tratado (por exemplo, médico do trabalho ou Diretor do banco), pode ser tido como portador de um discurso representativo, formador de opiniões e/ou formulador de políticas.

Para lançar diferentes luzes que matizem os temas em estudo, procurou-se, também, colher material jornalístico pertinente, bem como material de propaganda interna, editado pela própria empresa.

A pesquisa, concluída a transcrição das fitas, acha-se em fase de organização e análise do material recolhido. 